\title{
The Influence of Customer Lifestyles on the Decision of Choosing Online Design Studio Services
}

\author{
Benedicta Adriela \\ Magister of Design \\ Universitas Komputer Indonesia \\ Bandung, Indonesia \\ benedicta.adriela@email.unikom.ac.id
}

\begin{abstract}
The objectives of this research was to find out the influence of customer lifestyles on their decisions in using the services of online design studios. In order to know whether the use of the service is due to preferences, and finally to know whether it's influenced by the lifestyle or not. For that, research method used is qualitative research method with approach of sociology. So the results obtained from this study, there are eight lifestyles and each of it affects customers in deciding to use the services of online design studio than offline. The use of design studio services is also influenced by the preferences of each type of lifestyle, judging by the questionnaires given to the respondents. Each respondent gave answers on their preferences of the design elements and four images of each of the online design studios as research objects. From the questionnaire, can be known lifestyle type and the reasons of each respondent in determining the image and design studio which one that they like. So it can be concluded based on the type of lifestyle occurs, then the most dominant lifestyle is the lifestyle of the Achievers on making decisions today and chooses to use the services of an online design studio.
\end{abstract}

Keywords - Lifestyle, Design Studio, Preference

\section{INTRODUCTION}

Lifestyle is a person's life pattern which expressed in activities, interests, and opinions [1]. Society's lifestyle leads to modern urban life that is demanded the existence of completeness, convenience and practicality in effort fulfillment of life necessity. Different backgrounds of family structure, education, occupation, income, culture and religion will shape the lifestyles of diverse societies. Conscious or unconscious, these lifestyles will affect the environment around them, including the design world itself. The selection of design, color and shape of a product is determined by culture, in this case the customer's lifestyle. Things become an easy and convenient way is the appearance of online design studio services. Design studio services that require customers to come directly to the location of course less practical and easy. This is what started the appearance of online studio services that are easy to find on the internet. Even for ordering the design is quite easy, can be through email, social media, and website design studio services. Offline design studio services began to make its design studio into an online design studio to see the lifestyle changes customers who choose the ease of online systems.

There are similar studies that have been carried out by previous researchers as references. Noni Nevi Kanisa, researched the influence of lifestyle on consumer decisions in using photo studio services. In this study, lifestyle seems to influence consumers' decision to use photo studio services in Yogyakarta [2]. Tommy Kurniawan Njoto researched the influence of packaging design, taste, and product variation on the customer purchase decision of Bumi Anugerah. In this journal it can be concluded that packaging design, taste, and product variations have a significant effect on consumer purchasing decisions [3]. Susy Budi Astuti researched lifestyle transformation in the aesthetics of interior design, which proves that lifestyle is strongly influenced by environmental factors. Different environmental backgrounds will lead to different lifestyles [4]. Debora Kaharu and Anindhyta Budiarti examined the influence of lifestyle, promotion and product quality on purchasing decisions in Cosmic. The most influential factor on purchasing decisions is the quality of a product, but lifestyle and promotion also have a significant and positive influence on purchasing decisions [5]. Budi Sandra, Ice Kamela, and Rika Desiyanti examined the influence of lifestyle factors, product design, product features on the purchase decision of Oppo smartphones in the city of Padang. In this study lifestyle did not significantly influence the purchasing decisions of Oppo smartphones and what was influential was product design and product features [6].

But because in the study no one discusses the influence of consumers' lifestyles on the decision to use online design studios, this research will be suitable for research, the purpose of this research is to find out the influence of customer lifestyles on their decisions in using the services of online design studios, to know whether the use of the service is due to preferences, and finally to know whether it's influenced by the lifestyle or not. To support, research method used is qualitative research method with approach of sociology. Hopefully, this research will be useful for design studios, customers, and researches. This research will be useful in understanding customers lifestyles as an evaluation material in designing, and also as a reference in determining superior 
design strategies that will come according to customers preferences.

\section{METHOD}

\section{A. Research Type}

This research used qualitative research methodology, because it is based on several considerations. Especially in the focus and problems in this study covers the meaning, motives, reasons, and goals that exist on the basis of choosing a design studio service. The qualitative approach used the sociology approach. The sociology approach in qualitative research methods seeks to uncover the socio-cultural meaning and experience of research subjects towards a phenomenon that cannot be easily measured using numeric.

Sociology of design itself can be interpreted as the study of thought processes and the realization of the work related to the values of a society's relationship [7]. Descriptive sociology research is a research that seeks to describe and interpret something, for example the conditions or relationships that exist, opinions that developed, the ongoing process, the effects that occur, or about the ongoing trend.

Descriptive analysis can use frequency distribution analysis which is concluded based on average results. Descriptive research results are often used, or continued with analytic research. The types of research included in this category are case studies and survey research. To obtain complete and objective data, the researcher also conducted field research, which examined directly to the object of research, namely consumers and design studios.

There are 40 respondents, from various backgrounds. Divided from gender, age, education, work, and hobbies. Of the 40 respondents, 4 pictures were given from the two online design studios, namely Kabita Studios and Oray Studios, which were intended to find out the reasons for making their choices, even though some still chose to use offline design studio services.

\section{B. Place}

This research was conducted in 2 (two) Online Design Studios located in Bandung, namely:

\section{Kabita Studios}

Kabita Illustration Studios or abbreviated as Kabita Studios is a home studio business that is engaged in illustration. Initially it was an individual illustration service from September 20, 2013 and began operating as a team on April 1, 2014 under the name Kabita Studios. This studio is located at Jl. Pangauban no. 154, RT 03 RW 08, Katapang, Bandung.

\section{Oray Studios}

Oray Studios is a remote graphic design studio that was founded in February 2008, where they decided to open a design studio along with 3 more artists so that Oray Studios started with 5 members. This studio is located at Jl. Cemara no. 22, Pasteur, Sukajadi, Kota Bandung.

Both of these studios are the right studios because they have stood for a long time and have quite a lot of consumers who use their studios. With the duration of standing, the research on the influence of consumers' lifestyles in the decision to use the studio can be seen.

\section{Time}

This study will examine design studios and consumers in 2016, and then compare in 2018 to see the development of customer lifestyles that occur. This research was conducted in less than one year, from February to June 2018, then the method used was cross-sectional survey. That is a data collection method (which is also one of the descriptive research methods) where information is collected only at a certain time. What is meant by data collection is not only one day, but can be done in a few days or even weeks because of the situation [8].

\section{RESULTS}

Table I is the lifestyle's type that occurred to 40 respondents who were used as samples. The type of the lifestyle is using VALS instead of Acorn Classification.

Acorn classification is a market research company which breaks down the population in a myriad of different ways in order to allow companies to analyze and create and construct their target market / target audience more effectively and costeffectively than ever [9].

VALS (Values and Lifestyles) is a proprietary research methodology used for psychographic market segmentation. VALS is a way of viewing people on the basis of their attitudes, needs, wants, beliefs and demographics. By using psychology to analyze and predict consumer preferences and choices, the VALS system constructs a link between personality traits and buying behavior. The system identifies current and future opportunities by segmenting the consumer market place on the basis of the personality traits that drive consumer behavior [10].

TABLE I. THE RESPONDENT LIFESTYLE'S TYPE

\begin{tabular}{|l|l|l|l|l|}
\hline \multicolumn{1}{|c|}{ Lifestyle } & \multicolumn{1}{c|}{ Woman } & \multicolumn{1}{c|}{ Man } & \multicolumn{1}{c|}{ Total } & \% \\
\hline Achievers & 10 & 3 & 13 & 32,5 \\
\hline Anxious & 5 & 4 & 9 & 22,5 \\
\hline Affluent & 7 & 1 & 8 & $20 \%$ \\
\hline Loners & 3 & - & 3 & 7,5 \\
\hline Pusher & - & 3 & 3 & 7,5 \\
\hline Attention Seekers & - & 2 & 2 & $5 \%$ \\
\hline Pleasure Seekers & 1 & - & 1 & 2,5 \\
\hline Socialite & - & 1 & 1 & 2,5 \\
\hline Total & 26 & 14 & 40 & 100 \\
\hline
\end{tabular}

There are 8 lifestyles from the 40 respondents and can be seen in Table II, that in the present more people choose to use the online design studio than those who are offline.

TABLE II. The Design Studio’s Type By Respondent LifESTyle

\begin{tabular}{|l|l|l|l|}
\hline \multicolumn{1}{|c|}{ Lifestyle } & \multicolumn{1}{c|}{ Online } & Offline & \multicolumn{1}{c|}{ Both } \\
\hline Achievers & 7 & 4 & 2 \\
\hline Anxious & 1 & 8 & - \\
\hline Affluent & 7 & 1 & - \\
\hline Loners & 3 & - & - \\
\hline Pusher & - & 2 & 1 \\
\hline Attention Seekers & 2 & - & - \\
\hline Pleasure Seekers & 1 & - & - \\
\hline
\end{tabular}




\begin{tabular}{|l|l|l|l|}
\hline Socialite & - & 1 & - \\
\hline Total & 21 & 16 & 3 \\
\hline
\end{tabular}

There are differences in decision choosing using online design studio and offline. The difference in decision choosing, customers can be seen from trusting with the first impression when looking at the online studio portfolio. When customers still lack of trust in the portfolio and the studios, customers will choose offline studio services.

TABLE III. The SELECTION OF DESIGN StUdio BASED ON LifESTYLE

\begin{tabular}{|l|l|l|}
\hline Lifestyle & Kabita & Oray \\
\hline Achievers & 12 & 1 \\
\hline Anxious & 7 & 2 \\
\hline Affluent & 4 & 4 \\
\hline Loners & 1 & 2 \\
\hline Pusher & 1 & 2 \\
\hline Attention & 2 & - \\
\hline Pleasure & 1 & - \\
\hline Socialite & 1 & - \\
\hline Total & 29 & 11 \\
\hline
\end{tabular}

Then in table III from the eight types of lifestyles many chose to use Kabita Studio compared to Oray Studios. For good color composition, bright and bright colors, good color contrast, simple and original style, kids friendly images, consistent style (similarity in shape, line, color).

There are also some lifestyle factors that come from external (environment, and others), and there are also from internal (self). Of course this factors will make a difference type of lifestyle in making decisions on the chosen online design studio. When concluded from the respondent's data obtained, it can be made as Table IV.

TABLE IV. THE LIFESTYLE'S FACTORS THAT INFLUENCE DECISIONS

\begin{tabular}{|l|c|c|c|c|}
\hline \multicolumn{1}{|c|}{ Lifestyle } & Trust & Preference & Portfolio & Testimony \\
\hline Achievers & $\checkmark$ & $\checkmark$ & $\checkmark$ & - \\
\hline Anxious & - & $\checkmark$ & $\checkmark$ & $\checkmark$ \\
\hline Affluent & $\checkmark$ & $\checkmark$ & $\checkmark$ & - \\
\hline Loners & $\checkmark$ & $\checkmark$ & $\checkmark$ & - \\
\hline Pusher & - & $\checkmark$ & $\checkmark$ & - \\
\hline Attention Seekers & $\checkmark$ & $\checkmark$ & $\checkmark$ & $\checkmark$ \\
\hline Pleasure Seekers & $\checkmark$ & $\checkmark$ & $\checkmark$ & - \\
\hline Socialite & - & $\checkmark$ & $\checkmark$ & - \\
\hline
\end{tabular}

It can be concluded that there are lifestyles that have high trust and those who do not. For preferences and portfolios, all lifestyles required it in decision making. There are also lifestyles that require encouragement or testimony from others to decide whether he will use online or offline design studio services.

The highest trust holders are Lifestyle Achievers, Affluent, Loners, Attention Seekers, and Pleasure Seekers.
These five lifestyles have different levels of trust compared to other lifestyles that still lack trust in online design studios. For other lifestyles, they still can't trust online design studio services even though they have seen the portfolio. It can also be concluded that the current level of trust has increased due to the development of lifestyle.

Color can also be one of the decision factors as in the Table $\mathrm{V}$ which shows that each lifestyle has its own type of color preferences.

TABLE V. COLORS PREFERRD By THE LIFESTYLE'S TyPE

\begin{tabular}{|l|l|l|l|l|l|l|}
\hline Lifestyle & Red & Yellow & Green & Blue & Brown & Pastel \\
\hline Achievers & 2 & - & 1 & 4 & 3 & 10 \\
\hline Anxious & 1 & - & 1 & 4 & 3 & 6 \\
\hline Affluent & 2 & 1 & 1 & 4 & 1 & 8 \\
\hline Loners & - & - & 1 & 1 & 1 & 1 \\
\hline Pusher & - & - & 1 & 1 & - & 2 \\
\hline Attention Seekers & - & 1 & - & 1 & - & - \\
\hline Pleasure Seekers & 1 & - & - & - & - & 1 \\
\hline Socialite & - & - & - & 1 & - & - \\
\hline Total & 6 & 2 & 5 & 16 & 8 & 28 \\
\hline
\end{tabular}

\section{DISCUSSION}

Next is analyzing one by one design from each studio and equate it with the type of lifestyle that chooses the desired online design studio. But to be short, we can analyzed two design from each studio. For analyzing, we are divided it using color, style, composition, and design elements. Different colors are perceived to mean different things [11], including style, composition, and design elements. They will be some aspect that will divided each lifestyle.

\section{A. Kabita Studios}

Kabita Studios has comical style which kids friendly and can be liked by all ages. 


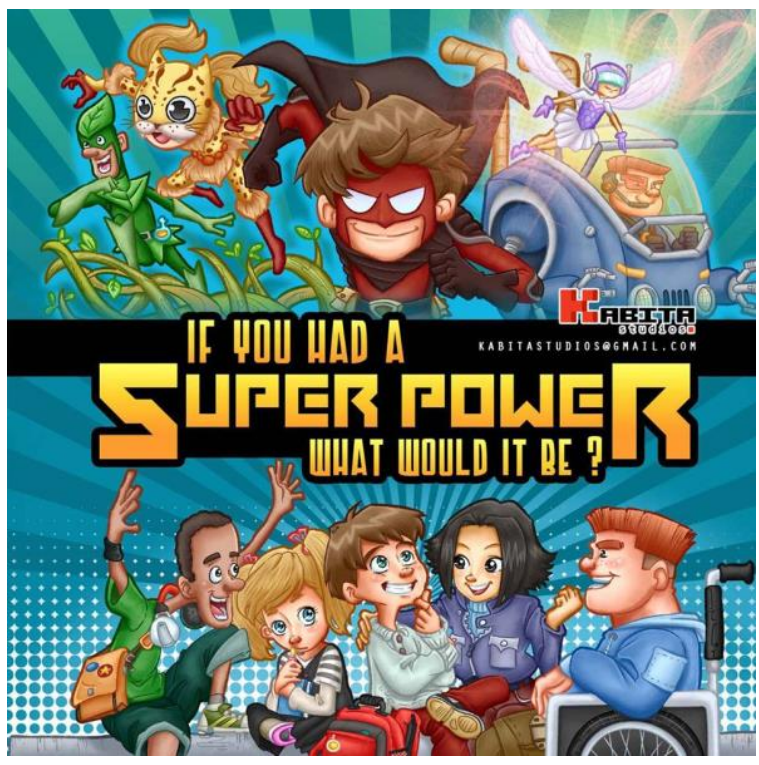

Fig. 1. Kabita Studio Design (1)

We can see the color that is most used is the blue color that is graded with green at the top. The colors for each character are red, yellow, green, purple, and blue, although they are dominated by blue, but the color combinations that occur are quite integrated.

The color of each character is quite in accordance with the meaning of the color. Like a character dressed in green having natural strength because green does have symbolic value to nature. Characters dressed in yellow are adapted to tiger animals that are indeed yellow. The character in red is associated with fire which can be seen in the image of the character below carrying the flame symbol on the bag. Purple jacketed characters, although not discussed in the discussion of the meaning of the colors above, purple means sensitive, compassionate, understanding and supportive, not infrequently associated with sacred things. So that the purple character turns into a fairy, quite appropriate because we can see his supportive nature. The character in blue is also in accordance with the meaning of blue which is professional in nature which can also be associated with technology.

Titles are yellow so they stand out to be seen and read first before looking at the image behind them.

There are lines that look focused on one point. This is done to provide focus that determines the center of the image. The lines are also combined with spheres that add a non-boring effect.

The style of the cartoon syle character picture is liked by all ages.

Besides that, this picture also gives morality that every child has the right to have the dream of wanting to be in the future. Because it is shown that the child in blue is a child who uses a wheelchair so that he is lacking, but he has the same dream as other children.

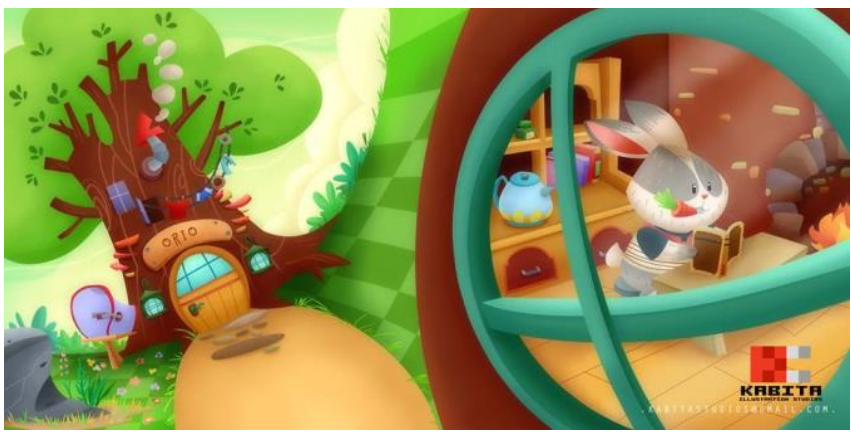

Fig. 2. Kabita Studio Design (2)

The dominant color in this picture is brown and green. Equipped with other colors that give a more aesthetic feel.

Green color is used for grass and leaves of trees which is in accordance with the meaning of green that is close to nature. While the brown color is used on tree trunks, roads, floors, tables, to shelves that you can know that it is wood. Brown has an earthy, strong, and durable impression when used as furniture.

The grass is seen to be given a line, and the curve that can indicate the center of focus is the tree that is on the left, but the image on the right can be analyzed that it is an inner form, even though it may be less obvious due to lack of components.

Looking at the tree house, it can be concluded that inside the tree there are some who live because there is smoke from the funnel connected to the tree house. There is also a post box to receive letters, and the name on the tree house that we can conclude from the tree house belongs to Orio.

Orio itself can be concluded as a rabbit in the right picture. We can see that the activity is eating carrots while reading a book. Also seen is the cooked kettle that you can imagine its contents are water that is being cooked. There is also a burning fireplace there, which seems to influence why there is smoke from the tree funnel.

From the whole picture, it can be seen that this picture is telling a story about a rabbit named Orio who lives in a tree house. From the style we can see that there is a high probability that this picture is intended for children and for all ages.

When viewed as a whole, the one who chooses Kabita Studios from all lifestyles is $73 \%$. The acquisition was obtained from Achievers lifestyle types of 92\%, Anxious $78 \%$, Affluent $50 \%$, Attention Seekers $100 \%$, Loners $33 \%$, Pushers 33\%, Pleasure Seekers 100\%, and Socialite $100 \%$. With this we know how many percent of these lifestyle types like the style of Kabita Studios, especially from the most lifestyle's types in the present, the Achievers as many as $92 \%$ who choose Kabita Studios. But for Attention Seekers, Pleasure Seekers, and Socialite who get $100 \%$ choose Kabita Studios are less valid because of the lack of respondents with that lifestyle.

Many of the respondents chose Kabita Studios because:

- Good color composition

- Bright and cheerful colors

- Contrast color intertwined well

- Simple and Original style 
- Children's friendly pictures (Kids Friendly)

- Consistent style (similarity of shapes, lines, colors)

\section{B. Oray Studios}

Oray Studios has a professional look and liked by grown people because of its concept.

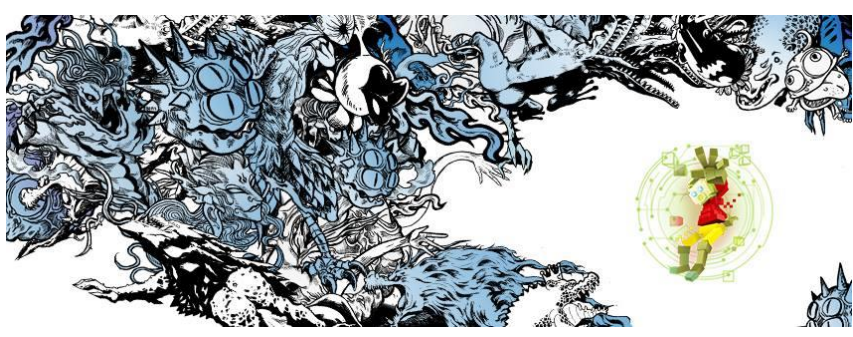

Fig. 3. Oray Studios Design (1)

The most dominant color here is the blue color given to the monsters around the image. But there are also red, yellow and green colors given to one character that is the main focus of the picture.

The monsters which in blue colour when referring to the meaning of blue can mean, an authority, as well as sadness and depression. It could be that this monster gives sadness to every creature. So that a different colored character appears from them to hold the sadness deeper and fight it. The monster also varies in shape, it could be concluded as various kinds of problems that hit a human.

Characters that have different colors themselves, look like they consist of squares, different from the monsters that are more dynamic. The color of the character consists of red which means brave, yellow which means energy, and green which means supportive. With these colors, we can conclude that the character is a different main character than the monsters around him. The character gives its own color in the image that makes it look energetic, brave and supportive, ready for any situation.

Then in the colored character background, you see circles in the shape of a pattern combined with small circles, lines, and squares. The circle strengthens the colored character as the main focus. Besides that the circle looks like the strength of the character which is dominated by green which means as a supportive.

This picture can be read as motivation even though many problems come, we can still go through it with courage, energy, and supportive attitude from others.

This picture style can be for all ages, even though it is more towards teenagers to adults to understand the meaning of this picture.

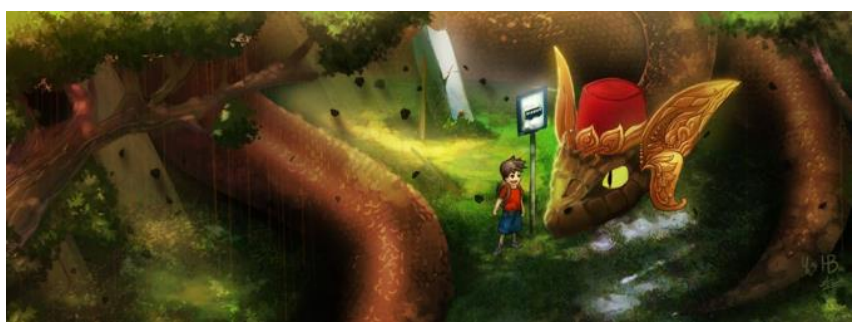

Fig. 4. Oray Studios Design (2)
The color in the image is dominated by green and brown, and is complemented by red, gold and blue. Even so the image looks dark because it shows that they are in a deep forest so that the light is difficult to enter.

The giant snake is brown which can mean that this snake is a grounded and strong snake when taken from the meaning of its own brown color. In the head of the snake there is a gold and red crown which symbolizes wealth and strength. So it can be concluded that the snake is king in the forest.

There is one boy who wears red clothes and blue pants. The red color on his shirt could mean that he was brave, seen the boy looked smiling and not afraid when approached by the giant snake. Whereas the blue color can mean calm which means he is a pretty calm and brave child.

Between the child and the snake, there is a sign of a stop for the bus. By looking at the sign, I can conclude that the child is actually waiting for a bus, but his enormous imagination makes him seem to be in the forest where when the bus appears, what appears is a giant snake in the child's mind.

Style on the picture for all ages because of the fantasy that makes children to adults like the picture.

When viewed as a whole, then choosing Oray Studios from all lifestyles is $27 \%$. The acquisition was obtained from the Achievers lifestyle type as much as $8 \%$, Anxious 22\%, Affluent 50\%, Loners 67\%, and Pushers 67\%. With this we know what type of lifestyle that likes the style of Oray Studios, especially for Loners and Pusher who both reach $67 \%$. But the data is less valid because of the lack of respondents with this lifestyle.

Many of the respondents chose Oray Studios because:

- Clear concepts and delivery

- clear character

- Bold color contrast and coloring techniques

- Composition and color make it comfortable

- Life and style can vary depending on order

We can concluded that the two design studio services have different styles. Kabita Studios has a cartoon style that is loved by children because they have a focus on designing and making illustrations of children's story books. While Oray Studios has a variety of styles that focus on the style of each consumer who uses their services. After knowing the analysis of each studio, we can also know what style is being favored by the types of lifestyle of the respondents.

Like the similar studies and researches, lifestyle is strongly influenced by environmental factors. Different environmental backgrounds will lead to different lifestyles [4] and lifestyle seems to influenced the consumers decision to use the services [2], in this research is to use the online studio services.

\section{CONCLUSION}

From the results of the analysis that has done, it can be concluded that if viewed based on the type of lifestyle that occurs, then now the most dominant lifestyle is the lifestyle of the Achievers. This lifestyle is the lifestyle that makes the most decisions today. This lifestyle chooses to use the services of an online design studio by choosing Kabita Studios, and there are three lifestyle factors that help customers choose are the trust factor, preferences, and portfolios. 


\section{ACKNOWLEDGMENT}

Thanks to Dr. Yeffry Handoko Putra, S.T, M.T, Dr. Abay D. Subarna, and Prof. Yusuf Affendi Djalari, as Mentor Lecturer from UNIKOM who has guided me from beginning to the end that greatly improved the journal. Thanks to Kabita and Oray Studios that gave a lot of data of their works for me to made this journal.

\section{REFERENCES}

[1] Philip T. Kotler and K. L. Keller, "Marketing management," $13^{\text {th }}$ Edition, NJ : Pearson, 2009.

[2] Noni Nevi Kanisa, "The Lifestyle influence and reference groups on customers decisions using photo studio services", Universitas Sanata Dharma, Yogyakarta, 2017.

[3] Tommy Kurniawan Njoto, "The Influence of packaging design, taste, and product variation on purchasing decision Bumi Anugerah consumers," Manajement Journal and Businness Start-Up, 2016.
[4] Susy Budi Astuti, "Lifestyle transformation on interior design aesthetics," Institut Teknologi Sepuluh Nopember, Surabaya, 2017.

[5] Debora Kaharu and Anindhyta Budiarti, "The Influence of lifestyle, promotion and product quality on cosmic manufacturing purchasing decisions," Sekolah Tinggi Ilmu Ekonomi Indonesia, Surabaya, 2016.

[6] Budi Sandra, Ice Kamela, and Rika Desiyanti, "Lifestyle factor influence, product design, product features on the purchase of oppo smarthphones in the Padang City," Universitas Bung Hatta.

[7] Agus Sachari, "Design Sociology," Erlangga, Jakarta, 2002.

[8] Ronny Kontour, "Research Methodology," PPM Jakarta, 2004.

[9] Bradford, Greg, "Acorn Classification System for Lifestyle," United Kingdom : Insite, 1997.

[10] Raj, Mohan, M. Prasanna, and A. K. Sait, "Psychographic Profiling of Indian Young Adult Consumers of Smartphone-VALS Approach." Management Studies and Economic Systems 2, no. 2, 2015.

[11] Aslam, M.M, "Are You Selling the Right Colour? A Cross-cultural Review of Colour as A Marketing Cue." Journal of Marketing Communications, 2006. 